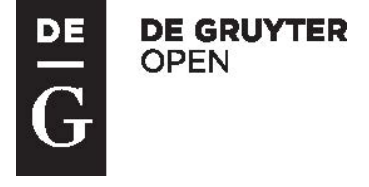

LINGUACULTURE, 1, 2017

\title{
THE ROLE OF THE MEDIA IN BAZ LUHRMANN'S ROMEO+JULIET
}

\author{
NICOLETA-MARIANA IFTIMIE* \\ Gheorghe Asachi Technical University of Iași
}

\begin{abstract}
Hailed by some and passionately criticized by others, Baz Luhrmann's Romeo+Juliet (1996), one of the best known cinematic adaptations of Shakespeare's story of the "starcross'd lovers" has appealed to the young audiences because it succeeded in intermingling the delivery of Shakespeare's language with the modern discourse promoted by late $20^{\text {th }}$ century media, particularly television and journalism. Different types of media pervade the movie from the outset to its very end: the black screen at the beginning makes room in its centre to a TV set, which moves forward into the viewer's space, while displaying a newscaster who delivers the play's Prologue in a monotone; in a symmetrical manner, the image of the television set appears again at the end and we see the newscaster delivering the last lines of the play. After the lines are recited, the television set gets smaller and smaller, until it fades away and the screen becomes black. The whole movie is thus embedded into a news programme; the news story is located as the one which is being witnessed by the viewer in real time.

The paper will analyze the role of the television and printed media in the unfolding of Baz Luhrmann's Romeo+Juliet, with a view to point out its impact on the textual and visual structure of the movie.
\end{abstract}

Keywords: Romeo and Juliet; media; television; printed media; cinematic discourse.

\section{INTRODUCTION}

Shakespeare's plays have represented a source of inspiration for many film adaptations. Romeo and Juliet makes no exception: on the contrary, as it has been pointed out, "Romeo and Juliet has been filmed more often than any other play, Shakespearean or otherwise" (Brode 42). The series of screen adaptations

\footnotetext{
*nicoletaiftimie@yahoo.co.uk
} 
of the play started in 1908 with Romeo and Juliet, a Romantic Story of the Ancient Feud Between the Italian Houses of Montague and Capulet, film directed by J. Stuart Blackton. The most notable film versions are George Cuckor's 1936 production featuring Leslie Howard and Norma Shearer, Franco Zeffirelli's 1968 film, which introduced for the first time two teenagers in the leading roles-Leonard Whiting, only seventeen, as Romeo, and Olivia Hussey, 15 years of age, as Juliet - and Baz Luhrmann's 1996 MTV-inspired movie Romeo + Juliet, featuring Leonardo di Caprio and the sixteen-year-old Claire Danes. While shocking the critics, Luhrmann's film delighted the young audiences, who could find in the characters, situations and setting a mirror of postmodern society. Pointing out the fact that Luhrmann's production targets generation X, Rothwell underlines the apparent incongruities in the movie: "it has been filtered through John Woo's Hong Kong action movies, and the hiphop and gangster rap of MTV, yet the characters speak in Elizabethan English" (241). In fact, it is probably this very intermingling of modern discourse at the level of the mise-en-scène, imagery and music promoted by and stirred through the media (MTV videos, South American telenovellas) on the one hand, and the preservation of Shakespeare's dialogue, on the other, that makes Luhrmann's film interesting for the young audiences.

Romeo+Juliet is permeated by the media, both in printed and audiovisual form, from the outset to the very end. This paper will focus on the role of television and journalism in Baz Luhrmann's Romeo+Juliet, with a view to point out its impact on the textual and visual structure of the movie.

\section{READING THE IMAGE: ROMEO AND JULIET'S STORY AS A NEWS PROGRAMME}

The movie starts with a black screen that makes room in its centre to a TV set, which moves forward into the viewer's space, while displaying a newscaster who delivers the Prologue of Shakespeare's Romeo and Juliet in a monotone; in a symmetrical manner, the image of the television set appears again at the end and we see the same newscaster delivering the last lines of the play. After these last lines are recited, the television set gets smaller and smaller, until it fades away and the screen becomes black. Hindle (178) argues that the whole substance of the film is thus contained by its status as item on a TV news programme, delivered from a 1970 style TV screen that appears at the opening of the movie. The movie is thus embedded into a news programme; the news story is located as the one which is being witnessed by the viewer in real time.

As Rothwell (230) points out, television can manipulate ordinary people into confusing reality and fantasy so that they can identify themselves emotionally with people they have never met before. The film succeeds in 
mixing and blurring together "multiple planes of perception"- the real world, the world of the movie, the world of "illusory television newscasts" (Rupar 27), thus making it difficult at times for an inexperienced spectator to choose from among these various planes of perception the "real" one.

\section{TELEVISION AS A FRAME OF REFERENCE}

Television as a medium of communication appears five times in Luhrmann's movie. The first instance coincides with the beginning of the film. The film starts with the logo " $20^{\text {th }}$ Century Fox", which introduces the spectator into the possible world created by Luhrmann and his team. This is quickly followed by the frame-within-a-frame technique, the television screen inside the black cinema screen which displays the same " 20 th Century Fox" logo in white letters against a black background. The television screen is the first unexpected element Baz Luhrmann's film introduces. Anyone familiar with Shakespeare's play might wonder at this point what might be the role of a television set in a film presenting the unhappy destiny of Romeo and Juliet. Such a spectator's expectations might be baffled again: instead of seeing the cast and the names of the other film practitioners as it is usual in a movie, we see an anchorwoman delivering The Prologue in a professional monotone, as if presenting a news programme or a weather forecast. While she is delivering the sonnet lines, on the right side of the screen we see the image of a broken ring with the caption "starcross'd lovers". Inside the ring we read the inscription "I love thee". When the anchorwoman finishes her speech, we plunge through the screen to the streets of Verona Beach and we hear a male voice that recites the "Prologue" again, while short video clips correlated with newspaper and magazine front pages briefly summarize the grudge of the two families. The newsreader frames the topic, then there follows the presentation of images and "actuality" from "out there" at the street level in the form of a two-hour documentary.

Thus, the beginning of the movie marks a contradictory movement with respect to the relationship real world - cinematic world - the world of television news. From the very beginning we see the logo " $20^{\text {th }}$ Century Fox" followed by "A Bazmark Production" and we are thus introduced into the possible cinematic world created by Luhrmann and his team. This is quickly followed by the framewithin-a-frame technique, the television screen inside the black cinema screen which displays the anchorwoman delivering The Prologue in a manner resembling the news program. Therefore, the fake possible world of the cinema introduces us into the fake possible world of television broadcast, which, in its turn, presents "real" and tragic events that have just happened involving a pair of "star-cross'd lovers". This makes it possible for a spectator who is less accustomed to Shakespeare's play to mistake the opening of Luhrmann's movie version of Shakespeare's tragedy for real TV news. However, several lines of 
Shakespeare's Prologue recited by the anchorwoman bring back the idea of artistic make-believe world:

The fearful passage of their death-mark'd love

And the continuance of their parents'rage

Which, but the children's end, nought could remove,

Is now the two hours'traffic of our stage; (Prologue 9-12)

Then we are immersed into the world of Verona Beach, dominated by a monumental statue of Christ, placed at the top of a column in the centre of a circus surrounded by two high office buildings named Capulet and Montague, respectively. There follows a quick succession of images, some of which are blurred, and a return to the face of the statue of Christ which suddenly freezes as a photograph on the front page of a tabloid, The Verona Beach Herald, surrounded by the photos of the Montagues on the left and those of the Capulets on the right. A male voice starts reciting the first six lines of the Prologue again, while short news footage covering the outbreak of the feud between the Montagues and the Capulets correlated with still images of magazine front covers and big-sized editorial headlines from Verona Beach Herald and other newspapers briefly summarize the grudge of the two families. Such devices are meant to recreate the idea of "reality", while also populating the cinematic universe-of discourse with past events and characters that will be shortly introduced as members of the cast.

\section{CHARACTERS AS SPECTATORS: WATCHING THE NEWS}

In Luhrmann's movie, television also plays a functional role for the characters, i.e., that of informing them on the latest "news". Thus, the second, third and fourth instances when television appears as a means of communication are embedded in the plot as such.

The news about the latest fight between the Capulets and the Montagues is received by Fulgencio Capulet and Romeo by means of television. While sitting at his desk, his back towards the screen (and the spectators), Fulgencio Capulet, Juliet's father, hears the sound of helicopters flying above the city. He takes the remote control and switches on his television set, while also turning his face towards the television set (and the audience) in order to watch the news: the television screen displays the same African-American newsreader we saw several minutes before reciting again the third line of the Prologue "From ancient grudge break to new mutiny" (Prologue 3). At the bottom of the screen we may read " $3{ }^{\text {rd }}$ Civil Brawl" and to the right we see a photo representing Benvolio, Romeo's cousin, a gun in his hand. The scene is very short, lasting for about three seconds. 
Later on, Romeo finds out about the same fight between the Capulet and Montague "boys" from a 1970 television set conveniently placed on a table on the beach, while walking around accompanied by his cousin and friend, Benvolio. It is interesting to notice that Benvolio, although a participant in the fight, did not inform Romeo about it. So Romeo is actually witnessing the fight and its consequences on a TV monitor placed on the beach. There is no newsreader on the screen this time. What Romeo and the spectators see are only short clips showing scenes from the fight and the intervention of the police forces.

A few minutes later, Romeo and his cousin Benvolio find out from television about the feast at the Capulets' mansion, while playing pool at The Globe. This news is delivered alternatively by two Caucasian reporters, a woman and a man; it is in fact an invitation to the feast addressed to the well-to-do in Verona Beach, on condition they do not belong to the House of Montagues: "If you be not from the House of Montague, come and crush a cup of wine!"

\section{CLOSING THE "PROGRAMME": A MIRROR IMAGE}

The end of the movie, which is a mirror-image of the beginning, uses once again the trick of the television broadcast. The death of the two lovers is followed by a brief scene involving the Prince screaming "All are punished" (5. 3. 295), while the two corpses covered in white sheets are brought down by paramedics on stretchers and introduced in an ambulance. The image is a bit fuzzy and this makes us "realize" at this point that we are watching the footage of a documentary or a news broadcast: the image of the television set in the opening scene of the movie appears again and we can watch the same African-American newscaster delivering in a monotone the last six lines of the play, which in Shakespeare's text are attributed to the Prince of Verona. The television set gets smaller and smaller until it fades away and the movie screen becomes black. By doing this, Luhrmann reminds the audience that they are watching a movie-a postmodern touch congruent with the meta-theatricality used by Shakespeare in many plays. According to Elsie Walker (2002), the film's epilogue trivializes the great tragic action of the play. However, one might argue that the newsreader's speech delivered in an emotionless monotone is a purposeful device used in Luhrmann's movie, an invitation to reflect on the ability of the media to get detached from the facts presented, and as such to deprive a tragic event of meaning. Commenting on the final scenes of the film, Geoffrey Way points out that the device of the newscaster delivering the first and the last lines adds a tone of irony to the movie 
alerting the audience that they are watching a series of events unfold that have actually already occurred, and then reminding them of the fact that the events that occurred were unavoidable. At the same time, Luhrmann reminds his audience that they are watching a film, a reminder that plays with the metatheatricality that Shakespeare often used in his own plays. (2007: 30)

\section{PRINTED MEDIA: WHAT'S IN THE NEWS?}

Baz Luhrmann's film is also permeated with printed media, usually presented as a quick succession of newspaper cuts or a generous display of magazines. Such elements play an important role in delineating the universe-of-discourse in terms of location, characters, their relationships and past events.

The first appearance of printed media can be noticed soon after the anchorwoman has finished delivering the lines of the Prologue. After a quick succession of Verona Beach cityscapes, the image presenting the statue of Christ dominating the centre of the city freezes as a photograph on the front page of The Verona Beach Herald, surrounded by the photos of the Montagues on the left and those of the Capulets on the right. The arrangement of photos suggests from the very beginning a divide between the two families. In these photos, the two heirs - Romeo and Juliet - have a childish appearance; this means that the issue of Verona Beach Herald is old, and so is the grudge between the two families. The lines of the Prologue, reiterated by a man in an opera-style soprano voice, are meant to remind the spectator of the feud existing for a long time between the Capulets and the Montagues. The last line recited by the male voice, "A pair of star-cross'd lovers take their life" (Prologue, 6), just like line 9 of the same Prologue uttered earlier by the anchorwoman, suggests that a terrible fate is in store for lovers whose relationship is neither favoured nor blessed by the stars. Thus, from the very beginning of Shakespeare's play or of Luhrmann's movie, the theatre - or cinema-goer will know how the play/the film ends. The audience knows, but the main characters do not. In Luhrmann's movie, Shakespeare's concept of fate is preserved, being portrayed to modern audiences by means of modern media. While the voice is reciting the first six lines of the sonnet at the beginning of Shakespeare's play, the spectator is bombarded with newspaper editorials from various printed media (The Verona Beach Herald, Verona Today, The People's Eye) that point to the history of violence linking the two families: Montague vs Capulet, Ancient Grudge, New Mutiny, Civil Blood Makes Civil Hands Unclean. Intertextuality is obvious-with the exception of the first headline, all the others are taken from Shakespeare's Prologue.

The re-contextualization of words taken from Shakespeare's Prologue into newspaper headlines may serve another purpose as well: that of bringing together, albeit sometimes in a cheeky manner, High Culture (as represented by Shakespeare) and "low" (pop) culture, as represented in this case by tabloid 
articles. However, as Robert Hapgood shows, Shakespeare himself was a popularizer, "[t]ransferring from page to stage and from narrative to drama some of the central writings of his time" (84). As a result, Baz Luhrmann felt free to become in his turn a "re-popularizer" of Shakespeare's play that presented the tragic fate of the two "star-crossed lovers".

The quick succession of newspaper cuts is followed by a series of magazines (Timely, Prophesy, Bullet) whose main articles are about violence and all kinds of bloody deeds.

The purpose of this first series of printed media is to provide a context and to introduce the spectator into the world of violence between the two families. The headlines presented in a quick tempo, together with the images suggesting riot, destruction and chaos depict a violent background against which the action is placed.

\section{“ADD MORE FUEL TO YOUR FIRE"}

Phoenix gas station is the place where the action corresponding to Act I in Shakespeare's play really starts. This gas station, the modern counterpart of what Shakespeare's play calls "a public place", is the spot where the conflict between the two households is rekindled. A close-up of Tybalt, dressed in a black leather jacket, a brown cigarette between his lips and the sound of a match falling down (in the perimeter of Phoenix gas station) - all these are elements meant to anticipate what is going to happen. The allusion is only too clear and is reinforced by Benvolio's staring at the gas station slogan that says "Add more fuel to your fire." A few minutes later, when the fight between the Capulet and the Montague boys reaches its climax, we see how gas from the Montagues' car spills down and is lit by Tybalt's cigarette. At this moment, the news stand with copies from Worldly News and (probably) The Verona Beach Herald is put on fire, together with the banner advertising the news "Montague vs Capulet: $2^{\text {nd }}$ Youth Brawl" and the slogan bearing the memorable words "Add more fuel to your fire." In an ironic manner, newspapers get a new function in this scene, i.e. that of fuel added to the violent feud of the two households. Still another role can be attributed to printed media: that of recording events in chronological order. The previous section mentioned several newspaper headlines and editorials pointing to the feud existing between the Capulets and the Montagues. The first one, taken from The Verona Beach Herald was entitled Montague vs Capulet. It included photos of the two family members in which the younger ones-Romeo and Juliet, respectively-appeared as young children, which means that this particular newspaper is an older issue, which traces down the history of the grudge between the two families. The banner at the gas station advertises the newspapers on the stand as "Montague vs Capulet: $2^{\text {nd }}$ Youth 
Brawl", which leads us to believe this is a new brawl in the series. As mentioned above, Fulgencio Capulet finds out about the fight at the Phoenix station from a television set placed in his office at the bottom of which we may read " $3{ }^{\text {rd }}$ Civil Brawl". Therefore, the role of the media is also that of recording important events chronologically, in order to offer a diachronic picture of what happened.

\section{FROM “PRECIOUS BOOK OF LOVE” TO COVER BOY}

Luhrmann's movie is full of Shakespearean intertextual allusions-various signifiers placed in a new textual or visual context, which thus acquire a new meaning or are just taken playfully in their literal meaning.

This is the case with Paris. The character's name has undergone some changes in the movie - he is called Dave Paris. There are also some changes regarding his relationship to other characters: in Shakespeare's play he is "Nobleman" and "Kinsman to the Prince" (Shakespeare 301), while the film cast presents him as "the Governor's son". In Act I, Scene 3 of Shakespeare's play, Lady Capulet tries to convince her daughter, Juliet, to marry Paris, in spite of her very young age. In order to do that, she prizes the young man's qualities and calls him "This precious book of love, this unbound lover, / To beautify him, only lacks a cover" (1.3.87-88). The film takes this idea literally and provides Dave Paris a real cover, introducing him as a cover boy, featured as Timely's "Bachelor of the Year". The role of printed media here is an ironic and playful one. The scene which displays the issue of Timely magazine is placed on the beach. We can see an overweight Hispanic newsagent, sitting near an improvised news stand. One can notice several copies of The Verona Beach Herald and Worldly News and also some copies of magazines, such as Prophesy and Timely. The next shot is a close-up of Timely featuring Dave Paris as "Bachelor of the Year". A few minutes later, the same issue of Timely magazine with Paris on its front cover is shown to Juliet by her mother, in what might correspond to Act I, Scene 3 in Shakespeare's play. This time the roles of the printed media are to inform the young daughter about the existence of a handsome young man who wants to marry her and to convince her to accept the husband chosen for her by her parents. A cover boy featured by Timely, a supposedly well-known magazine will surely be, in the Capulets' view, an eligible young man for Juliet.

\section{CONCLUSIONS}

The purpose of this paper has been to analyze the role of the media in Baz Luhrmann's William Shakespeare's Romeo+Juliet. Out of the media presented in the movie, two main types have been dealt with-television and printed 
media - with a view to showing their impact on the textual and visual structure of the film, as well as their function in the cinematic discourse at large.

The paper has dealt with five instances in which television appears as a medium of communication in Luhrmann's movie: 1) at the beginning of the movie; 2) at the end of the movie; 3) when Fulgencio Capulet finds out about the fight between the Capulet and the Montague boys; 4) when Romeo learns about the brawl at the gas station; 5) when Romeo, as well as his cousin and friend Benvolio learn about the ball at the Capulets. As it has been pointed out, television plays different roles in the economy of the film: a) it can act as a frame of reference, i.e. it creates the context against which the action of the movie unfolds - a documentary or an item on a TV news programme; b) it can be regarded as a modern reminder of implacable fate; c) it represents an ironic hint at the detachment and lack of emotional involvement of television professionals; d) it is a modern means of briefing the characters on the latest events.

Printed media can be said to occupy a special place at the beginning of the movie when the cinematic discourse alternates short cityscapes and images of chaos and violence with newspaper clips in order to introduce the would-be viewer into the possible world of Shakespeare's tragedy as re-contextualized by Baz Luhrmann and his team. Thus, the role of printed media in these scenes is to delineate the universe-of-discourse in terms of location, characters, their relationships and past events.

Another role of printed media in the film structure, this time in close connection to television, is to point out the succession of events and their development. Finally, if we think about Paris and his presentation through the medium of a magazine as cover boy featured in Timely's "Bachelor of the Year", one can argue that printed media can also perform an ironic, playful function in Luhrmann's adaptation of Shakespeare's play.

\section{Works Cited}

Brode, Douglas. Shakespeare in the Movies. New York: Oxford University Press, 2000. Print.

Hindle, Maurice. Studying Shakespeare on Film. New York: Palgrave Macmillan, 2007. Print.

Hapgood, Robert. "Popularizing Shakespeare: the Artistry of Franco Zeffirelli in Shakespeare on Film." Shakespeare the Movie: Popularizing the Plays on Film. Eds. Lynda E. Boose and Richard Burt. London: Routledge, 1997. 80-94. Print.

Romeo+Juliet. Directed, co-produced and co-written by Baz Luhrmann. $20^{\text {th }}$ Century Fox, 1996. 
Rothwell, Kenneth, S. A History of Shakespeare on Screen, Cambridge: Cambridge University Press, 1999. Print.

Rupar, Alja. Metatext in Movies: The Case Study of Baz Luhrmann's William Shakespeare's Romeo +Juliet (1996), Ljubljana, 2010, http://docplayer.net/23001719-Metatext-in-movies-the-case-study-of-bazluhrmann-s-william-shakespeare-s-romeo-juliet-1996.html. Web. 29 Sept. 2016.

The Illustrated Oxford Shakespeare. London: Chancellor Press, 1991. Print.

Walker, Elsie. "Pop Goes the Shakespeare: Baz Luhrmann's William Shakespeare's Romeo+Juliet”. Literature/Film Quarterly 28.2 (2002): 132-139. Print.

Way, Geoffrey. "Wherefore Art Thou, Romeo?: A Study of Three Late TwentiethCentury Film Adaptations and Appropriations of Romeo and Juliet" (2007). All Theses. Paper 116. http://tigerprints.clemson.edu/cgi/viewcontent.cgi?article= 1116\&context=all_theses. Web. 16 Sept. 2016. 